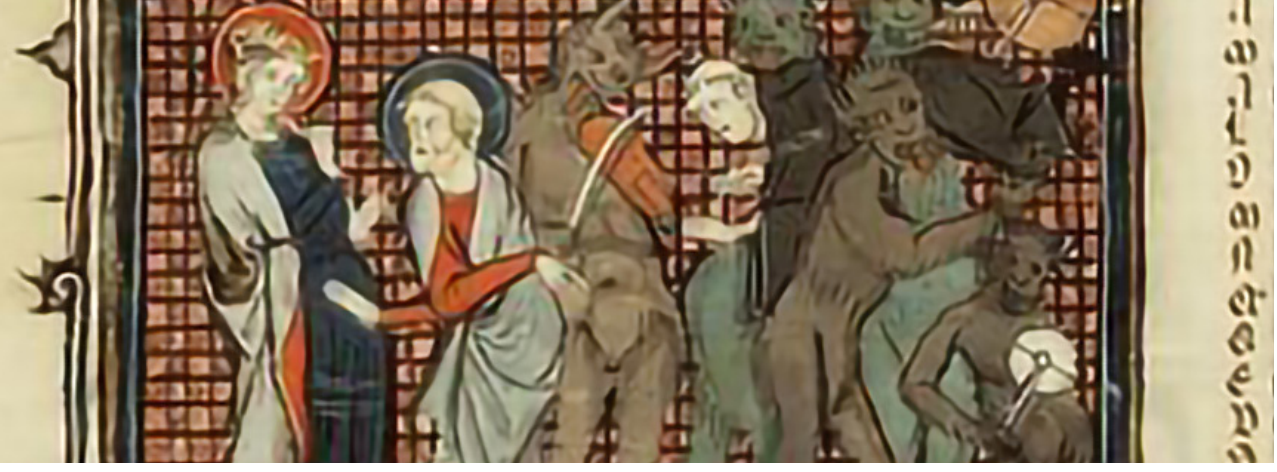

\section{Inmanencia y Trascendencia en Juan Escoto Eriúgena}

Immanence and Transcendence in Juan Escoto Eriúgena

\section{Resumen}

En el presente trabajo nos proponemos transitar la metafísica de Juan Escoto Eriúgena, partiendo de la noción que considera más adecuada para nombrar la totalidad de las cosas: el término latino 'natura'. Abordaremos la cuádruple distinción que se establece a partir de esta noción en su obra 'De divisione naturae', en la que se resume el proceso por el cual todo sale de Dios y todo termina volviendo a Dios. Intentaremos mostrar el modo en que la doctrina del Eriúgena oscila entre una concepción inmanente de Dios en el mundo basada en la vía catafática y una concepción trascendente de Dios respecto del mundo fundada en la vía apofática, estableciendo una tensión dialéctica que no logra resolverse por carecer el autor de una adecuada comprensión de la participación ontológica y de la analogía en la predicación lógica.

\section{Palabras clave}

Juan Escoto Eriúgena, Dios, mundo, inmanencia, trascendencia.
Profesor de Filosofía egresado de la Universidad Católica Argentina y Diseñador de Imagen y Sonido egresado de la Escuela Panamericana de Arte. Trabajo actualmente como profesor en varias cátedras en UCALP y en CONSUDEC. Entre mis últimos artículos publicados se encuentran: 'Dasein, Existenz, In-der-Welt-sein' en revista 'Persona' (2019), 'A propósito del lenguaje inclusivo' en revista 'Tábano' (2019), 'El conocimiento simbólico en Gottfried Leibniz' en revista 'Studium' (2018) y 'La originalidad de la ontología tomista y su giro en torno al ser' en revista 'Studia Gilsoniana' (2018).

\section{ORCID \#}

\begin{abstract}
In this paper we intend to explore the metaphysics of Juan Escoto Eriugena, starting from the notion that he considers most adequate to name the totality of things: the Latin term 'natura'. We will address the fourfold distinction that is established from this notion in his work 'De divisione naturae', which summarizes the process by which everything leaves God and everything ends up returning to God. We will try to show the way in which the doctrine of Eriúgena oscillates between an immanent conception of God in the world based on the cataphatic way and a transcendent conception of God with respect to the world based on the apophatic way, establishing a dialectical tension that cannot be resolved due to lack of the author of an adequate understanding of ontological participation and analogy in logical predication.
\end{abstract}

\section{Keywords}

Juan Escoto Eriúgena, God, world, immanence, transcendence.
Recepción de artículo: 23-4-2019

Aceptación del artículo: 3-9-2020

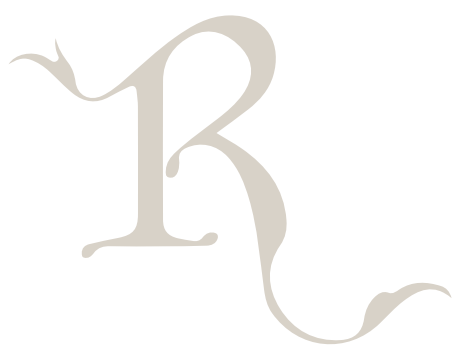




\section{INTRODUCCIÓN}

El ejercicio de la razón en relación con lo mundano, lo humano y lo divino constituye el tema central del pensamiento de Juan Escoto Eriúgena (810-877). Este irlandés, cortesano de Carlos el Calvo en la Francia del siglo IX, asume una intelectualidad que fusiona filosofía, teología y mística, en una reflexión que busca la divinización del hombre, puesto que a su entender "nadie entra en el cielo sino por medio de la filosofía." Sabido es que su obra fue condenada por el Concilio de Paris de 1210 y que el Papa Honorio III exigió que todas las copias de sus obras fueran llevadas a Roma para ser quemadas en 1225. En ellas se incluían interpretaciones heterodoxas de ciertas cuestiones teológicas, como afirmar la salvación universal de todo ser humano, sostener que el infierno no es más que un estado de conciencia, declarar que el pecado de Adán ha sido fruto de una distracción en vez de un acto voluntario, aseverar que la división de la especie humana en sexo masculino y femenino es consecuencia del pecado original, asegurar que ni siquiera en lo que denominamos visión beatífica tendremos contemplación del rostro divino y manifestar que las Sagradas Escrituras están sujetas a infinitas interpretaciones por haber sido escritas por un autor también infinito. Tales ideas le han dado mala fama en los ámbitos cristianos de entonces, aunque más recientemente ha sido rescatada su figura por esta tradición religiosa, por ejemplo en boca de Joseph Ratzinger. ${ }^{2}$

Entre sus influencias neoplatónicas cristianas cabe mencionar a Dionisio Areopagita, Máximo el Confesor y Gregorio de Nisa.

En Dionisio halló la idea de la teofanía, del universo como una manifestación de la divinidad y un empleo cabal de la vía negativa mediante la cual se niega que Dios sea alguna de las cosas que pueden ser pensadas o dichas. En Máximo, la dinámica de dos nociones solidarias que habrían de convertirse en los pilares de su filosofía: procesión y retorno. Y en Gregorio, una concepción del ser humano que exalta su condición de imagen divina. ${ }^{3}$

Sin embargo, el Eriúgena recibe influencia neoplatónica tanto en su versión cristiana como en su versión pagana, de manera que autores como Plotino, Porfirio y Proclo también deben contarse entre los que resuenan en sus escritos. Incluso, en gran medida nos parece que la obra erugeniana representa una síntesis original y equilibrada de ambas tradiciones dentro del neoplatonismo. "Por primera vez en Occidente se encuentran estas dos dimensiones del neoplatonismo y su fruto más importante en esta época estará en el pensamiento de Juan Escoto Eriúgena". ${ }^{4}$

El lector que se sumerge en sus escritos se encuentra con una lógica férrea al momento de hablar de Dios en términos de unidad, simplicidad, eternidad, infinitud y absolutidad. Sin embargo, enumerando características similares a las del ser parmenídeo, el Eriúgena advierte que se piensa en un 'Dios estático', lo cual sólo se supera introduciendo la noción cristiana de creación en el seno mismo de la divinidad, cuestión que lo lleva a pensar en un 'Dios dinámico' que, al crear el mundo, se crea a sí mismo. Para comprender mejor estas ideas, debemos hacer referencia a la noción de naturaleza y a la cuádruple distinción hecha por nuestro autor en su obra capital, titulada 'Periphyseon' o 'De divisione naturae', que resume el proceso por el cual todo sale de Dios y todo termina volviendo a Dios.

\section{LAS DIVISIONES DE LA NATURALEZA}

La filosofía erugeniana parte de la noción que considera más adecuada para nombrar la totalidad de las cosas: el término latino 'natura' que equivale al griego ' $\phi v \sigma ı \varsigma^{\prime}$, el cual designa "la suma de las cosas que son y de las que no son." ${ }^{5}$ Esta división corresponde a lo que nuestro intelecto puede conocer y lo que no puede conocer, esto es, por un lado, al ámbito de lo finito y lo limitado que es lo que cae bajo nuestro alcance, por otro lado, al plano de lo infinito y lo ilimitado que supera nuestras capacidades. En resumidas cuentas, lo que podemos conocer es lo que puede ser captado por nuestra sensibilidad y nuestra intelectualidad, como los individuos espaciales y temporales o las especies y los géneros inteligibles, en tanto que lo que no podemos conocer es, básicamente, la esencia de la divinidad: Dios está más allá de las capacidades de nuestra comprensión y de nuestro lenguaje.

El universo erugeniano abre, entonces, un camino hacia lo finito y hacia lo infinito, organizándose en una multiestratificación ontológica que reconoce los siguientes órdenes: Dios, los ángeles, los hombres, los animales, los vegetales y los minerales. Sin embargo, a esta escala jerárquica en el universo se llega después de haber partido de la noción de naturaleza y de haber diferenciado cuatro especies dentro de tal género. "Me parece que la división de la naturaleza asume cuatro especies mediante cuatro diferencias. De esas, la primera es la que crea y no es creada; la segunda, la que no sólo crea sino que también es creada; la tercera, la que es creada y no crea; la cuarta, la que ni crea ni es creada." ${ }^{6}$ Es evidente que el criterio de esta división supone la noción cristiana de creación y señala cuatro ámbitos de indagación en la obra erugeniana que representamos esquemáticamente:

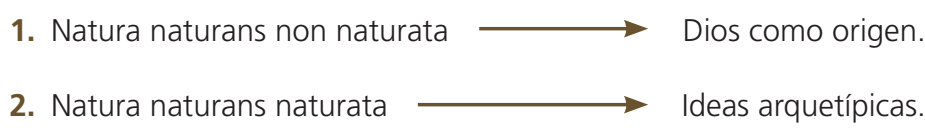

2. Natura naturans naturata Ideas arquetípicas

3. Natura non naturans naturata $\rightarrow$ Mundo espiritual y material.

4. Natura non naturans nec naturata $\longrightarrow$ Dios como meta.

1. Escoto Eriúgena 2016, 'Anotaciones a Marciano', LVII, 15. Este mismo estilo de síntesis especulativa la practicarán Meister Eckhart en el siglo XIII, Nicolás de Cusa en el siglo XV y Jacob Böhme en el siglo XVII, para quienes en materia de fe no es necesario sacarse los ojos para poder ver con claridad.

2. Por ejemplo, este discurso pronunciado por Benedicto XVI: http://es.arautos.org/view/show/5033-benedicto-xvi-dedica-catequesis-de-la-audiencia-general-a-juan-escoto-eriugena-

3. Ludueña Ezequiel 2016, p. 61

4. Strok 2009

5. Escoto Eriúgena 2016, 'Periphyseon', I, 441 A

6. Ibídem I, 441 B 
En este esquema está implícita la doctrina aristotélica de las cuatro causas: la primera y la cuarta especie de esta división representa a Dios mismo en tanto causa eficiente y causa final, la segunda corresponde a las causas formales extrínsecas y la tercera a las causas materiales y las causas formales intrínsecas. "Los términos 1 y 4, si se reflexiona, designan la misma realidad que es Dios. Los términos 2 y 3 pueden agruparse bajo la denominación común de creatura. "7 Esta cuádruple distinción de la naturaleza genera un ciclo de procesiones en el que Dios se expresa en las ideas arquetípicas y, a través de éstas, en las cosas creadas tanto espirituales como materiales, para resumir todo lo expresado en un retorno ulterior hacia sí mismo. Sin embargo, "no debe calificarse este despliegue de la naturaleza como una concepción emanantista y panteísta, por más que sea cierto el fondo neoplatónico del Eriugena. Las cosas proceden de Dios por creación y a Él retornan como a un fin, pero sin perder su individualidad." 8 El universo es una expresión de la gloria de Dios y exhibe lo uno a través de lo múltiple, en un proceso de explicación y complicación que tiene a Dios como el alfa y el omega. "La multiplicidad del universo no es sino el despliegue de una fuente primigenia que, paradójicamente, está en un absoluto más allá de todo, siendo, a la vez, la causa de todo." 9

\section{NATURA NATURANS NON NATURATA}

Con la expresión latina 'Natura naturans non naturata' el Eriúgena se refiere a Dios como origen. Con respecto al conocimiento que podemos tener sobre Dios, el pensador irlandés hereda de Dionisio Areopagita la doble vía de su teología mística: la vía afirmativa y la vía negativa, siendo ambas complementarias a la hora de hablar sobre la divinidad. Por un lado, el supuesto de la 'vía afirmativa' es la creación, esto es, Dios como causa y el mundo como su efecto, lo cual habilita a la predicación analógica, porque entre causa y efecto debe existir cierta proporción. Por otro lado, el supuesto de la 'vía negativa' es la trascendencia, la absolutidad y la infinitud de Dios, ser sin esencia y sin ningún tipo de limitación. De esta manera, estudiando lo creado podemos conocer al creador, avanzando desde la multiplicidad hacia la unidad y desde los efectos hacia la causa, acercándonos tan sólo asintóticamente, a la vez que negando de su ser las limitaciones, especificaciones y relatividades que encontramos en el mundo.

Juan Escoto Eriúgena comienza su estudio aludiendo a la etimología de la palabra Dios, pero no lo hace remitiéndose al latín 'Deus' sino al griego ' $\Theta \varepsilon \varsigma^{\prime}$ ', debido a su predilección por lo helénico sobre lo latino. El término presenta dos acepciones: el verbo 'theoro' que significa 'contemplar' y el verbo 'theo' que significa 'fluir'. Nuestro autor cree encontrar en la noción divina una confluencia de ambos significados, siendo el primero el que nos da la idea de un 'Dios estático' y el segundo el que representa un 'Dios dinámico'. En efecto, siendo inmutable y eterno, Dios fluye a través de todas las cosas, haciéndolas existir al impregnarlas con su espíritu, puesto que el ser divino es movimiento estático a la par que inmanencia trascendente respecto del ser de los entes mundanos.

El corre a través de todas las cosas y de ningún modo permanece fijo, sino que corriendo plenifica todas las cosas, tal como ha sido escrito: 'Su palabra corre rápidamente' (Salmos 147, 15). Y sin embargo, no se mueve en modo alguno. De Dios se dice, entonces, con toda verdad, que es movimiento estable y estabilidad móvil, pues permanece fijo en sí mismo de manera inconmutable, porque no abandona jamás su natural estabilidad, pero se mueve a través de todas las cosas, para que exista todo lo que por Él subsiste esencialmente, ya que su movimiento hace todas las cosas. ${ }^{10}$

En una palabra, Dios lo trasciende todo siendo inmanente a todo, es decir, está más allá de todo lo que existe siendo a la vez el que otorga el ser a todo lo que existe. "No puedo atribuirle a Dios el movimiento, a Él que es único y que es inmutable y que no tiene desde qué ni hacia qué moverse, ya que todo está en Él o, mejor, ya que Él es todo. Pero no puedo suprimir de Él el hacer, porque es el hacedor de todo." 11 Pareciera que no alcanza considerar a Dios en un 'sentido absoluto', esto es, como es en sí mismo y desde sí mismo, sino que se lo debe considerar también en un 'sentido relativo', esto es, como causa de lo creado y como es para nosotros. Según este planteo, la razón de ser de las cosas no está en ellas mismas y desde ellas mismas, sino en Dios como causa 'trascendente' y principio 'inmanente' del ser de las mismas. Mientras todo ente mundano se caracteriza por ser contingente y condicionado, sólo Dios se manifiesta como ser necesario e incondicionado.

\section{NATURA NATURANS NATURATA}

Con la expresión latina 'Natura naturans naturata' el Eriúgena se refiere a las ideas arquetípicas o causas primordiales.

Son ideas arquetípicas o causas primordiales las que los sabios divinos llaman principios de todas las cosas: la Bondad por sí, la Esencia por sí, la Vida por sí, la Sabiduría por sí, la Verdad por sí, el Intelecto por sí, la Razón por sí, la Virtud por sí, la Justicia por sí, la Salvación por sí, la Magnitud por sí, la Omnipotencia por sí, la Eternidad por sí, la Paz por sí y todas las demás virtudes. ${ }^{12}$

Juan Escoto Eriúgena sostiene que estas ideas son creadas por Dios y que a través de ellas se crea todo lo que hay en el mundo, ya que sirven de modelos o prototipos eternos para las cosas mundanas temporales. Se encuentran en la mente divina y de ellas se dice que son creadoras, porque dejan pasar a través suyo la acción productiva de la divinidad, funcionando como principio de pluralidad, dado que la unidad divina se multiplica a través de ellas en géneros y especies. "La naturaleza divina no sólo crea sino también es creada. En verdad, es creada por sí misma en las ideas arquetípicas o causas primordiales y, por eso, se

7. Jeauneau Eduard 1995, p. 36

8. Beuchot Mauricio 1987

9. Ludueña Ezequiel 2016, p. 66

10. Escoto Eriúgena 2016, 'Periphyseon', I, 452 D

11. Ibídem I, $516 \mathrm{~A}$

12. Ibídem II, 617 A 
crea a sí misma, esto es, comienza a aparecer en sus teofanías." 13

Comprender las ideas como arquetipos que habitan la mente divina es algo que el Eriúgena toma de San Agustín, aunque el obispo de Hipona negaba que estas ideas hayan sido creadas, porque ¿cómo puede haber algo creado en el interior mismo de la divinidad? A entender del irlandés, la esfera de las ideas arquetípicas o causas primordiales consistiría en una primera hipóstasis derivada intratrinitariamente al modo plotiniano. Aquí el Eirúgena mantiene una posición ambigua que se limita a señalar, apelando al dato revelado, a saber, que estas ideas arquetípicas o causas primordiales fueron creadas por el Padre en el Hijo, quien representa el $\Lambda$ oros, o sea, la mente divina. "Los elementos no proceden de la nada, sino de las ideas arquetípicas o causas primordiales, las cuales han sido hechas a la vez y de una única vez por Dios en la Palabra de Dios." 14 En este sentido, el conocimiento humano implica una participación finita, imperfecta y limitada de esas ideas infinitas, perfectas e ilimitadas, las cuales se expresan por medio de un lenguaje idiomático que el mismo Hijo pudo expresar cuando habitó entre nosotros. Por eso, "la fundamentación del lenguaje por las ideas consiste en que, independientemente del idioma o dialecto que empleemos, lo que hacemos al hablar es manifestar la idea interior o verbo íntimo que nos habita y, en definitiva, tratamos de expresar y reproducir la idea ejemplar divina. "15

En esta instancia el pensador irlandés expone un concepto de creación arraigado en la ortodoxia cristiana trinitaria. Según el dogma cristiano, Dios es unidad de esencia y trinidad de personas: el Padre, el Hijo y el Espíritu Santo. En la interpretación trinitaria subordinacionista del Eriúgena, el Padre engendra al Hijo de su misma sustancia y del amor de ambos espira el Espíritu Santo. ${ }^{16}$ Dado que Dios es unitario en esencia y trinitario en personas, la primera persona (el Padre, el Origen, la Esencia) produce las ideas arquetípicas o causas primordiales en la segunda persona (el Hijo, el Entendimiento, la Palabra) y éstas se plasman en las cosas mundanas por medio de la tercera persona (el Espíritu Santo, el Amor, la Circulación). Resumiendo, las ideas arquetípicas o causas primordiales son las ideas creativas que moran en la mente de Dios, aunque no se identifican con Dios porque lo divino es trascendente a lo creado, siendo ya las ideas arquetípicas o causas primordiales una primera instancia hipostasiada del ámbito de lo creado.

Esta naturaleza hipostática de las ideas arquetípicas o causas primordiales lleva a Juan Escoto Eriúgena a concebir la creación del mundo como una teofanía o manifestación de la divinidad. En efecto, en tanto que la idea tradicional de 'creación' remarca la producción total del ser a partir de la nada y la trascendencia divina respecto del mundo, Dios por un lado y el mundo por otro lado, la idea de 'manifestación' sugiere la expresión de la misma divinidad en decurso de las individualidades mundanas. Dicho de otro modo, la relación entre la causa y el efecto resulta más estrecha si se la piensa en términos de manifestación, acentuándose así la presencia de Dios en el mundo en detrimento de su distancia. Sin embargo, esta 'teofanía' no es una mera revelación 'ad extra' sino que implica un movimiento 'ad intra', puesto que "la esencia divina, en las cosas que crea desde sí, por sí, en sí y para sí, rectamente se dice que se crea." 17 En este sentido, en la creación del mundo está implicada, según el pensador irlandés, la autocreación de Dios.

La naturaleza creadora no permite que nada exista fuera de ella, porque fuera de ella nada puede existir, al contrario, contiene dentro de sí el todo que creó y el todo que crea. Sin embargo, entiendes esto de manera tal que piensas que una cosa es ella y otra cosa lo que crea, pues no te parece verosímil que se cree a sí misma. ${ }^{18}$

Al efectuar el acto creador del mundo a través de las ideas arquetípicas o causas primordiales, Dios hace patente algo que estaba latente en su propio ser, siendo la nada de la que saca el ser del mundo no otra cosa que su misma esencia. De esta manera, todas las cosas mundanas participan del lo divino, sin llegar a multiplicar ni a dividir su esencial unidad.

Aunque no abandona la propia simplicidad y la singular unidad, el rayo divino se multiplica hermosamente y procede hacia aquellas realidades que han sido previstas de antemano para establecer una anagógica y unificante proporción. Pues nada subsistiría ni retornaría a su Principio si aquél rayo inefable no se difundiera en todas las cosas, a fin de que todo subsista. $Y$ al multiplicarse así ordenadamente, es decir, al proceder hacia todas las cosas, permanece en sí mismo, resguardado, inconmutable, similar a sí mismo. ${ }^{19}$

\section{NATURA NON NATURANS NATURATA}

Con la expresión latina 'Natura non naturans naturata' el Eriúgena se refiere al mundo espiritual y al mundo material creado. El mundo en su totalidad proviene de Dios por difusión de su superabundancia, en este sentido nuestro autor se pliega al concepto clásico de emanación, aunque en su doctrina la creación del mundo es un acto voluntario de la divinidad y no una decantación necesaria de una esencia destinada a hipostasiarse. En efecto, crear es sinónimo de causar y de participar: el creador es a lo creado como la causa es al efecto y como lo participante es a lo participado. "La participación no es otra cosa sino la derivación, a partir de una esencia superior, de una segunda esencia posterior a la primera, es decir, una distribución a partir de aquella que posee primero el ser a una segunda a fin de que esta exista." 20 El ser infinito y absoluto del creador es expresado en los seres finitos y relativos de las creaturas, para ilustrarlo se proponen varias analogías, entre ellas la del agua de un río. “El río entero mana

13. Ibídem, III, $690 \mathrm{~A}$

14. Ibídem, III, 665 B

15. Beuchot Mauricio 1987

16. Cfr. Giulio Máspero 2017

17. Eriúgena 2016, 'Periphyseon', I, 454 C

18. Ibídem, III, 675 A. A esta interpretación de la creación remite el panenteísmo de Karl Krause, quien pretendía conjugar la inmanencia y la trascendencia de Dios sobre el mundo.

19. Escoto Eriúgena 2016, 'Exposiciones sobre La jerarquía celestial', I, 134-135

20. Escoto Eriúgena 2016, 'Periphyseon', III, 632 B 
a partir de una fuente y, a través del lecho del río, el agua que surge primero en la fuente se difunde continuamente y sin interrupción hacia cualquier distancia que se extiende."21

Pero, hilando más fino en la cuestión, el pensador irlandés considera la creación desde dos perspectivas: en cuanto idea en la mente de Dios vinculada a las ideas arquetípicas eternas y en tanto creación efectiva localizada en el tiempo y en el espacio. "Acerca de la creatura se dará una doble intelección: una, por cierto, considera su eternidad en el conocimiento divino, la otra, en cambio, su instauración temporal en sí misma en un segundo momento." 22 Esto es así porque las cosas vistas desde Dios subsisten desde siempre como ideas arquetípicas, en tanto que vistas desde el mundo manifiestan un origen y un fin temporal. Entre las cosas que pueblan este mundo material encontramos minerales, vegetales, animales y humanos, teniendo todas ellas un tiempo y un espacio que las sitúa en un horizonte mundano determinado. Pero, ¿cómo es que surge este mundo material espacio-temporal a partir de las ideas arquetípicas en la mente divina?

Según el Eriúgena, el mundo material espacio-temporal surge de la falla que da lugar a una fragmentación de la unidad originaria, esto es, del pecado original. Adán vivía idealmente en Dios como idea arquetípica desde toda la eternidad, estando el resto de los seres humanos precontenidos en su idealidad de manera latente, así como también el resto de la creación. Y la relación de Adán con las demás ideas arquetípicas era inmediata, las conocía por mera intuición de su intelecto, sin necesidad de recurrir a los sentidos y conformando una totalidad unificada correlativa con las mismas. Pero esta situación ideal se vio interrumpida por la caída, un movimiento irracional a través del que Adán se distrae, pierde su atención y se queda dormido. Al despertar de ese sueño, Adán se encuentra con Eva y con este mundo material espacio-temporal que se nos manifiesta a los sentidos. "Así, pues, los cuerpos terminan surgiendo a partir de cosas incorpóreas." 23

Con la caída originaria, entonces, acontece la división de los sexos y la exteriorización en 'partes extra partes' de todos los seres mundanos respecto de los restantes. Se rompe la totalidad originaria, cada cosa se individualiza, quedando aislada y enfrentada a los demás. Y dado que todas las cosas fueron creadas a través del ser humano, su caída representa, a la vez, la caída de todas las cosas, la diferenciación y la multiplicación del paraíso de la identidad y la unidad, dando lugar a la aparición del mal metafísico, el mal físico y el mal moral. Muy en sintonía con el neoplatonismo, el Eriúgena evidencia cierto menosprecio hacia esta materialidad, aseverando que antes del pecado original nuestro cuerpo era puramente espiritual, mismo estado que presentará al resucitar, y que si no hubiese existido el pecado, no sólo el hombre sino el mundo entero seguiría siendo de naturaleza espiritual.

\section{NATURA NON NATURANS NEC NATURATA}

Con la expresión latina 'Natura non naturans nec naturata' el Eriúgena se refiere a Dios como meta. "Todas las cosas existen a partir de Dios, por medio de Dios, en Dios y para Dios. "24 Nuestro autor habla del retorno de todas las cosas a su origen: todo surge de Dios como principio absoluto y todo vuelve a Dios como fin absoluto, Dios es el Alpha y es el Omega y sus emanaciones están destinadas a reabsorberse en su propio ser. Este movimiento circular hay que concebirlo de modo ontológico y no cronológico: el origen y la meta son instancias simultáneas que se cumplen en todo momento en el presente viviente. "Hay un retorno general y uno especial: el general se da en todas las cosas que retornarán al principio de su instauración, y el especial, en quienes no sólo serán llamados a retornar a los orígenes de su naturaleza, sino que incluso fijarán el fin de su retorno en la causa de todas las cosas, Dios más allá de toda dignidad natural." 25

El sentido teleológico de la vida es muy diferente entre los paganos y los cristianos. Para los paganos el universo no tiene ni principio ni fin, en cambio para los cristianos hay un comienzo, un desarrollo histórico y un destino final. Para los paganos, los sucesos humanos son parte del orden cósmico, aunque el cosmos no se ocupa de sus avatares y sus peripecias. Para los cristianos, los acontecimientos humanos son parte de un historia universal que ellos mismos protagonizan, estando en juego su salvación o su condenación eterna. $Y$ si bien ha perdido la unidad originaria con Dios y con todos los demás seres a raíz del pecado, el ser humano está destinado a conquistar el paraíso perdido y a volver a la unidad originaria para él y para todos los demás seres mundanos. El hombre tiene la misión de reconducir el universo hacia su origen, porque a través suyo Dios creó la diversidad de las especies de los diversos órdenes.

Consta entre los sabios que en el ser humano se halla contenido todo lo creado. En efecto, entiende y razona como el ángel, siente y gobierna un cuerpo como el animal. En efecto, la totalidad de lo creado se divide en cinco secciones: corpóreo, vegetativo, sensitivo, racional e intelectual, siendo que de algún modo todo ello está contenido en el ser humano. ${ }^{26}$

Sin embargo, el hombre no puede por sus propios medios recuperar el paraíso perdido, por lo cual al mundo como teofanía natural se le suma la teofanía sobrenatural más clara de todos los tiempos: la

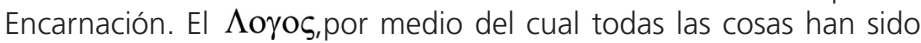
creadas, asume en el tiempo y en el espacio un rostro humano, a fin de salvar a los hombres y a la creación en su totalidad. Semejante misión salvífica encuentra su máxima manifestación, según la interpretación eriugeniana, en la gloriosa resurrección de Jesucristo, la cual representa la garantía del retorno de todos los seres a su fuente, incluidos los mismos demonios. Más allá de esta vida, el hombre se moverá en la divinidad al igual que el aire lo hace en la luz y Dios será todo en todo. Sin embargo, no consistirá este estado en una disolución de las individuales en la unicidad divina, sino más bien Dios reunirá en sí a todos los existentes en una transfiguración final sin confundirlos con su propia esencia.

21. Ibídem, III, $633 \mathrm{~A}$

22. Ibídem, III, 674 A

23. Ibídem, III, $663 \mathrm{~A}$

24. Ibídem, III, 679 A

25. Ibídem, V, 1001 B

26. Ibídem, III, 755 B 
Hay un primer regreso de la naturaleza humana cuando el cuerpo se disuelve y es restituido a los cuatro elementos del mundo sensible de los que está compuesto. El segundo, se cumplirá en la resurrección, cuando cada uno recobre su cuerpo por una comunión de los cuatro elementos. El tercero, cuando el cuerpo sea transmutado en espíritu. El cuarto, cuando el espíritu transmutado regrese a las causas primordiales que existen en Dios siempre. El quinto, cuando esta naturaleza, con sus causas se mueva hacia Dios como se mueve el aire en la luz. Entonces, cuando nada habrá sino sólo Dios, será al fin todo en todo. ${ }^{27}$

El ascenso y el descenso del alma desde Dios al mundo y desde el mundo a Dios representan un movimiento circular que integra lo múltiple en lo uno y lo uno en lo múltiple. Por vía descendente, el Eriúgena pasa de la unidad a la multiplicidad, dividiéndose el ser en géneros, especies e individuos. Por vía ascendente, el pensador irlandés parte de los individuos, pasando por las especies y los géneros hasta llegar de nuevo al ser. Este doble movimiento nunca termina y la ejercitación de la filosofía consiste en su continua alternancia. A este respecto, nunca hay que perder de vista que en su obra Juan Escoto Eriúgena no hace más que comentar la Escritura y especialmente el libro del Génesis, siendo la tarea de la razón en sí misma interminable, puesto que la variedad de sentidos de la Palabra Divina está sujeta a infinitas interpretaciones por su misma riqueza insondable. Por ende, este ejercicio filosófico y teológico representa un esfuerzo hermenéutico que nunca acabará por apuntar siempre hacia metas infinitas.

\section{INMANENCIA Y TRASCENDENCIA}

La vía afirmativa o catafática llevada al extremo acerca demasiado a Dios respecto del mundo. Es la vía por la que se afirma de lo divino lo característico de lo creado, evidenciando que la causa deja una impronta en el efecto. Y dado que Dios es causa de todo, contiene de antemano en tanto causa a todos sus efectos. "No creería que hay algo otro más allá de Dios y fuera de Dios. Por el contrario, en Dios está todo y fuera de Dios no hay nada." 28 Si Dios es el todo y todo es causado por Dios, entonces es ilimitado, incondicionado, absoluto y eterno. Así como todos los números subsisten en la unidad y todas las líneas en el punto, así también todos los entes finitos subsisten en el ser infinito como efectos de su causa.

Dios es todas las cosas en todas partes y todo en el todo, el hacedor y lo hecho, el que ve y lo que es visto, el tiempo, el lugar y la esencia de todas las cosas, no solo la sustancia sino también el accidente y todo lo que verdaderamente es y no es, el que comienza a ser por sí mismo y el que se mueve por sí mismo a sí mismo, el que se multiplica a sí mismo al infinito a través de los géneros y las especies sin abandonar la simplicidad de su naturaleza y haciendo regresar hacia sí la infinitud de su multiplicación. En Dios, pues,

\section{todas las cosas son uno. ${ }^{29}$}

Según la doctrina neoplatónica cristiana, Dios crea el mundo con deliberación y consentimiento, en tanto que, según la doctrina neoplatónica pagana, la acción divina es comparada con procesos impersonales y necesarios que dejan de lado el conocimiento y la voluntad. Pues bien, como ya dijimos, en el pensamiento de nuestro autor encontramos elementos de ambas tradiciones.

No debemos comprender al creador y a la creatura como dos realidades separadas una de la otra, sino como una y la misma. Pues no sólo la creatura subsiste en Dios, sino que además, al manifestarse, Dios se crea de un modo maravilloso e inefable en la creatura. Creador de todo y creado en todo. Hacedor de todo y hecho en todo. ${ }^{30}$

En su peculiar modo de comprender la causalidad, el Eriúgena insiste tanto en la similitud entre la causa y el efecto, en la imposibilidad de pensar ambas instancias aisladamente, que llega a afirmar en varias sentencias la identidad total entre la casusa y sus efectos, entre el creador y sus creaturas. "Dios es todo lo que verdaderamente existe, puesto que Dios hace todas las cosas y se hace en ellas. "31 De acuerdo a este razonamiento, Dios es todas las cosas y todas las cosas son Dios. Sin embargo, el pensador irlandés es consciente de que la presencia de Dios en el mundo no debe anular su distancia y, por este motivo, se autocritica constantemente. "¡Dios es todo! Pero, ¿todo es Dios? Esto será juzgado monstruoso por aquellos mismos que se consideran sabios, porque la diversidad de las cosas visibles e invisibles es múltiple, pero Dios es uno." 32

Si bien por medio de la vía catafática el Eriúgena acerca demasiado a Dios respecto del mundo, por medio de la vía apofática vuelve a despegar al mundo respecto de Dios. Uno de los caminos que toma para ello es la utilización de una analogía establecida entre la realidad divina y el intelecto humano. En efecto, para poder comunicarse con otros, el intelecto humano se expresa en pensamientos inmateriales que deben materializarse y articularse en palabras habladas o escritas, si es que quieren ser escuchadas o leídas.

También nuestro intelecto, aunque por sí mismo sea invisible e incomprensible, sin embargo es no sólo manifestado sino incluso comprendido a través de ciertos signos cuando se materializa, como a través de ciertos sonidos, ciertas letras o ciertas señales. Y mientras aparece así exteriormente visible, permanece interiormente invisible. $Y$ por esto, tanto calla como clama, y mientras calla, clama, y, mientras clama, calla. ${ }^{33}$

Puede verse un correlato entre la expresión de Dios y la expresión del intelecto humano porque, al igual que sucede con el ser divino, el intelecto humano es uno, espiritual y permanente, aunque se manifiesta en expresiones múltiples, materiales y cambiantes que pueden ser

27. Ibídem, V, 876 A

28. Ibídem, I, 516 B

29. Ibídem, III, 677 A

30. Ibídem, III, 676 B

31. Ibídem, III, $635 \mathrm{~A}$

32. Ibídem, III, $650 \mathrm{D}$

33. Ibídem, III, 634 A 
comunicadas a otros sin perder su identidad esencial. Esta analogía nos permite comprender que expresarse es, en cierto sentido, negarse, y que siempre hay algo que, en el interior de la expresión, permanece oculto y no puede revelarse. "La teofanía es así la afirmación de lo negado, el intelecto de lo inteligible, el cuerpo de lo incorpóreo, la definición de lo infinito." ${ }^{34}$ Al afirmarse en lo creado, Dios se niega como lo increado, su esencia huella lo material y lo espiritual, pero se repliega más allá de toda materia y de todo espíritu, se finitiza en el mundo, permaneciendo en sí misma infinita, se da un límite, estando siempre más allá de ese límite. En suma, Dios es todo del todo y también es nada del todo.

Así como por la vía afirmativa o catafática se arriba a la inmanencia de Dios en el mundo, así también por la vía negativa o apofática se llega a la trascendencia de Dios respecto del mundo. Pero estos resultados no valen lo mismo, porque "en el caso de las realidades divinas, la negación es verdadera, la afirmación no es verdadera, sino metafórica." ${ }^{35}$ Si bien, por un lado, hay una identidad entre la causa y el efecto, debido a la preexistencia del efecto en la causa, por otro lado, la causa supera el efecto, lo trasciende y se diferencia respecto de él. En este último sentido, la causa precede ontológicamente al efecto y no depende en absoluto del mismo.

La naturaleza divina no subsiste ni como género, ni como especie, ni como individuo. $Y$, sin embargo, todas esas cosas se predican de ella, porque de ella reciben la capacidad de subsistir. Tampoco se dice que es la totalidad de todo esto, ya que supera la totalidad de toda creatura por la infinitud de su excelencia, porque la total totalidad ha sido creada por ella. ${ }^{36}$

En este sentido, el Eriúgena declara explícitamente la insalvable inadecuación entre la creatura y el creador, tan distantes entre sí como el ser y la nada. Y a propósito de la nada, el pensador irlandés sostiene que la nada a partir de la cual todo fue creado no designa otra cosa que la realidad del mismo Dios, por lo cual no escribe 'creatio ex nihilo', como suele hacerlo la tradición cristiana, sino 'creatio de nihilo', esto es, las cosas están hechas de nada, lo que quiere decir que están hechas de Dios.

Creemos que Dios de la nada hizo todo, a no ser que quizás, esa nada sea Dios mismo, el cual puesto que se eleva superesencialmente por sobre todo y es glorificado por sobre todo lo que se dice y se entiende, no sin razón se dice que es la Nada por excelencia, porque de ningún modo se encuentra entre el número de las cosas que son. Si, pues, Dios es a la vez todo lo que es y todo lo que no es, ¿quién dirá que Dios es o no es algo, cuando Dios es el ser de todas las cosas y es más que el ser? O si, por excelencia y no por privación, no es algo, se concluye que es Nada por su infinitud. ${ }^{37}$

Es absurda, ante los ojos del pensador irlandés, la concepción tradicional de la creación a partir de la nada, la cual entiende esta nada como ausencia total del ser en vez de ser entendida como el mismo ser apofático de la divinidad.

Siguiendo el método inaugurado por Dionisio Areopagita en 'De divinis nominibus', Juan Escoto Eriúgena intenta superar la dicotomía existente entre la vía afirmativa y la vía negativa en una vía superlativa que aplica a la síntesis de las vías anteriores la partícula 'super'. El proceder eriugeniano se basa en el dionisiano:

Dios es esencia, he aquí la afirmación. Dios no es esencia, he aquí la negación. Dios es superesencial, he aquí simultáneamente la afirmación y la negación. Pues, aunque en apariencia falta la negación, quien dice que Dios es superesencial, no dice que es, sino que no es, dice que no es esencia, pero que es más que esencia. ${ }^{38}$

Así, si decimos por vía afirmativa 'Dios es el ser' y por vía negativa 'Dios no es el ser', entonces por vía superlativa decimos 'Dios es el super ser'. Repitiendo las enseñanzas dionisianas, el Eriúgena nos dice que "de Dios se dice que es el ser, pero propiamente no es el ser, pues el ser tiene un opuesto, el no ser, en consecuencia, es super ser." 39 Dios está más allá de la síntesis misma de los contrarios, del ser y la nada, de la unidad y la multiplicidad, del cambio y de la permanencia, porque en Dios se superan todas las oposiciones: Dios es todo en el todo y nada en el todo. "Para referirse a la divinidad inefable e incomprensible, cualquier denominación con que la vista una, llega inmediatamente otra para desvestirla, pues Dios se encuentra más allá de toda oposición." 40

\section{CONCLUSIÓN}

Como hemos visto a lo largo de este trabajo, Juan Escoto Eriúgena nos invita a hablar sobre aquello de lo que no se puede hablar y sobre lo que más vale callar. Dentro de esta paradójica empresa ha llamado nuestra atención la alternancia con la que transita la vía catafática y la vía apofática a la hora de referirse a lo inefable. Hemos encontrado una tensión dialéctica que no se corta nunca entre el polo de la total inmanencia y el polo de la total trascendencia, tal vez por tener clara conciencia que la resolución de esta cuestión implica, por un lado, salvaguardar la presencia de Dios en el mundo, según aquello de San Pablo de que "existimos, vivimos y nos movemos en Dios" (Hch, 17, 28), y, por otro lado, respetar la distancia inconmensurable que separa al mundo respecto de Dios, según aquello de Salomón de que "los cielos y los cielos de los cielos no pueden contenerte" (Re, III, 8, 27). Eso hace que el pensador irlandés conciba alternativamente a Dios como 'Todo' y 'Nada', articulando la 'vía catafática' y la 'vía apofática', aunque sin llegar a una solución convincente.

Esta oscilación constante en su pensamiento amenaza con una caída en el panteísmo o en el pandeísmo, no llegándose a establecer una

34. Ludueña Ezequiel 2016, p. 116

35. Escoto Eriúgena 2016, 'Exposiciones sobre La jerarquía celestial', II, 155

36. Escoto Eriúgena 2016, 'Periphyseon', II, 589 B. Pareciera aquí atisbarse la distinción tomista entre el ser común de todo lo creado (esse commune) y el ser absoluto de donde todo proviene (Esse Subsistens).

37. Escoto Eriúgena 2016, 'Exposiciones sobre La jerarquía celestial', III, 262

38. Dionisio Areopagita 1990, I 14, 462 C

39. Escoto Eriúgena 2016, 'Periphyseon', I, 459 D

40. Strok Natalia 2009 
adecuada articulación entre el orden de lo creado y el orden de lo increado, por carecer nuestro autor de una doctrina ontológica de la participación del ser en los entes que se acompañe de una doctrina lógica que respete las analogías presentes en las estructuras formales de lo real. "En Eriugena hay univocidad o equivocidad, hay vía catafática o vía apofática. Se hace sentir la falta de la noción de analogía, con cuya presencia hubieran desaparecido muchas aparentes paradojas en el lenguaje eriugeniano sobre Dios." "41 Al no articular correctamente la relación entre Dios y el mundo por carecer de las categorías adecuadas, Juan Escoto Eriúgena termina en un planteo dialéctico en el que se comienza afirmando a Dios como el 'Todo' y en el que se lo termina considerando como la 'Nada', sin arribar jamás a una síntesis final productiva. "La tensión entre la postura para la cual Dios se identifica con la creatura y aquella para la cual la diferencia entre ambos es abismal e insalvable recorre el 'Periphyseon' de punta a punta." ${ }^{42}$

Al no disponer de un punto de vista participacionista y analógico, nuestro autor confunde en más de una ocasión al ser divino con el ser mundano. En efecto, el ser que se atribuye a Dios análogamente no es la noción abstracta del ser en general, a la que arriba el pensamiento al considerar el ser que todo lo que existe tiene en común. Esa es una idea general del ser, a la que arribó Parménides en los albores del pensamiento occidental, una idea con fundamento real, pero de ninguna manera atribuible a Dios. Tal idea es fruto de una abstracción lógica y no tiene correlato ontológico, dado que el ser del que podemos tener experiencia es siempre el ser de tal o cual ente, el cual es de suyo inconceptualizable. En este sentido, los entes no son reales porque sean géneros, especies o individuos, así como tampoco el ser es real por subsumir todos los géneros, las especies y los individuos. Por el contrario, el ser es real porque tiene actualidad propia más allá de la esfera del pensamiento que lo considera, lo define y lo clasifica. Y dado que el acto de ser funda el acto de pensar como uno de sus modos, el ser real no procede de la idea del ser, sino que la idea del ser procede del ser real por un proceso de abstracción que suprime diferencias genéricas, específicas e individuales.

Además el Eriúgena dice que Dios al crear se crea, porque supone que la causa cambia al producir sus efectos. "Dios mismo es no solo el hacedor de todas las cosas, sino que también es hecho en todas ellas." 43 Vemos acá una problemática concepción de la causalidad, puesto que el sujeto del cambio es siempre el efecto que depende en el acontecer o en el ser de la causa. Es el efecto el que muta pasando de la potencia al acto y permaneciendo la causa inmutable. "Si la creatura proviene de Dios, entonces Dios es causa y la creatura es efecto. Pero si la creatura es efecto y el efecto no es sino la causa hecho efecto, se sigue que, como causa, Dios se hace en sus efectos." 44 Con esta concepción equivocada, en vez de concebirse como una operación 'ad extra' de Dios, la creación termina concibiéndose como una operación 'ad intra', esto es, como un proceso esencial en la autoconstitución del ser divino. Sin embargo, el pensador irlandés no recae en que la relación causal real es el vínculo de dependencia en el ser que el mundo manifiesta respecto de Dios, en tanto que la conexión que va de Dios hacia el mundo es una mera relación de razón. Dicho en pocas palabras, es cierto que Dios crea el mundo, pero no es cierto que el mundo crea a Dios.

Más allá de estos comentarios críticos y otros disensos que puedan establecerse, pensamos que la figura de Juan Escoto Eriúgena es digna de ser rescatada y estudiada, por los audaces sondeos metafísicos que hemos comentado y por ciertas interpretaciones sugestivas del texto sagrado. Todo ello en una época de poca fertilidad para la ciencia, la filosofía y la teología en Occidente, como ha sido el renacimiento carolingio, época en la que florecían la ciencia, la filosofía y la teología en el mundo árabe. Síntesis original entre las vertientes neoplatónicas cristianas y paganas, el Eriúgena representa un punto medio importante en la trayectoria de esta tradición de pensamiento, la cual influirá fuertemente en autores de gran resonancia como Meister Eckhart, Nicolás de Cusa, Spinoza y Hegel. ${ }^{45}$

41. Murillo Ildefonso 1993

42. Ludueña Ezequiel 2016, p. 128

43. Escoto Eriúgena 2016, 'Periphyseon', III, 650 B

44. Ibídem, III, $686 \mathrm{~A}$

45. Cfr. Claudia D'amico 2008 


\section{BIBLIOGRAFÍA}

- Dionisio Areopagita, Obras completas, BAC, Madrid, 1990

- Juan Escoto Eriúgena, Anotaciones a Marciano (traducción Ezequiel Ludueña en 'Eriúgena', Galerna, Bs As, 2016)

- Juan Escoto Eriúgena, Periphyseon (traducción Ezequiel Ludueña en 'Eriúgena', Galerna, Bs As, 2016)

- Juan Escoto Eriúgena, Exposiciones sobre La jerarquía celestial (traducción Ezequiel Ludueña en 'Eriúgena', Galerna, Bs As, 2016)

- Ludueña, Ezequiel, Eriúgena, Bs As, Galerna, 2016

- Máspero, Giulio, La trinidad explicada hoy, Madrid, Rialp, 2017

- Jeauneau, Eduard, La Filosofía Medieval, Buenos Aires, Eudeba, 1995

- Beuchot, Mauricio, "Ontología y lenguaje en Juan Escoto Eriugena", México, Revista Ergo, Vol. 2 (1987)

- Murillo, Ildefonso, "El lenguaje sobre Dios en Juan Escoto Eriúgena", Revista Española de Filosofía Medieval, Vol. 1 (1993)

- D’Amico, Claudia, "Todo y nada de todo, Selección de textos del Neoplatonismo latino medieval", Buenos Aires, Winograd, Vol. 1 (2008)

- Strok, Natalia, "Dionisio Areopagita y Juan Escoto Eriúgena en torno a la teología afirmativa y negativa: el peso de la fuente", Argumentos: Revista de Filosofía, Vol. 2 (2009) 